\title{
One new troglophilous species of the genus Sinopoda (Araneae, Sparassidae) from Guizhou, China
}

\author{
Huiming Chen \& Mingsheng Zhu* \\ College of Life Sciences, Hebei University, Baoding Hebei 071002, China; \\ E-mail: hmchenspi@gmail.com; chenspi@yahoo.com.cn \\ * corresponding author
}

\begin{abstract}
One new species of the genus Sinopoda is described under the name of Sinopoda mi from a cave in Yanhe Tujia Autonomic County, Guizhou, southwestern China, with a note of its natural history.
\end{abstract}

Key words - Sparassidae, Sinopoda, new species, cave, Guizhou, China.

\section{Introduction}

Spiders of the family Sparassidae are ecribellate, entelegyne, and medium to very large in size; they are nocturnal, wandering spiders, which spin no web, but often build silk retreats (Song et al. 1999). The soft trilobate membrane dorso-distally situated on metatarsus is regarded as diagnostic and apomorphic character for this family. Members of this group are distributed worldwide with 83 genera and 1056 species recognized (Platnick 2008) and 87 species belonging to 10 genera are known in China.

The sparassid genus Sinopoda was established by Jäger (1999), who recognized 25 species including 14 undescribed ones from Japan, Korea, China, Thailand, Malaysia and east India as members of this genus. Sinopoda was revised in detail mainly in China and Japan; many new species were described and many known species were transferred to this genus by Jäger (1999), Jäger \& Ono (2000, 2001, 2002), Jäger \& Yin (2001), Jäger et al. (2002), Liu et al. (2008) and so on. Up to now, 37 species of this genus have been recorded, of which 29 species occur in China.

The purpose of this contribution is to describe one new species of Sinopoda from a cave in Yanhe County, Guizhou, southwestern China.

\section{Materials and methods}

All measurements were made at the widest or longest point of a structure and given in millimetres. Vulvae were carefully excised, placed in temporary mounts and cleared in warm solution of $\mathrm{KOH}$. Drawings of figures were made under a Spencer Buffalo microscope and a Tech XTL-II stereomicroscope equipped with an Abbe drawing device. Spine notation follows Davies (1994). Taxonomic descriptions and terminology follow Jäger (1999) and Jäger \& Ono (2000).

The acronyms and abbreviations used in the text are as follows: ALE: anterior lateral eye; AME: anterior median eye; AW: anterior width of carapace; $\mathrm{CH}$ : height of clypeus; OL: abdomen length; OW: abdomen width; PL: carapace length; PLE: posterior lateral eye; PME: posterior median eye; PW: carapace width; RTA: retrolateral tibial apophysis; SL: sternum length; SW: sternum width.

\section{Taxonomy}

Family Sparassidae Bertkau, 1872 Genus Sinopoda Jäger 1999 Sinopoda mi sp. nov.

(Figs. 1-7)

Types Material. Holotype: Male from Mi Cave $\left(28^{\circ}\right.$ $39.5^{\prime} \mathrm{N}, 108^{\circ} 10.1^{\prime} \mathrm{E}, 802$ metres above sea-level), Shapi village, Huangtu town, Yanhe Tujia Autonomic County, Guizhou province, 6 October 2007, collected by H. M. Chen. Paratype: One female, data are same as holotype. The specimens are deposited in the College of Life Sciences, Hebei University, Baoding, China (HBU).

Diagnosis. This new species is similar to Sinopoda triangula Liu, Li \& Jäger, 2008, but is distinguished from the latter by the slender embolic apophysis (Figs. 2-4), whereas in S. triangular the embolus has a triangular structure on apical part, and the head of spermatheca arises from middle of basal part (Fig. 7), whereas the head arises from distal part in S. triangula.

Description. Male (holotype). PL 5.41, PW 4.79, AW 2.54, OL 6.32, OW 3.67. Eye sizes and interdistances: AME 0.20, ALE 0.25, PME 0.20, PLE 0.28, AME-AME 0.20, AME-ALE 0.15, PME-PME 0.33, PME-PLE 0.43, AME-PME 0.38, ALE-PLE 0.40, CH (AME) 0.45, CH (ALE) 0.35 , SL 2.55, SW 2.60. Spination as in Table 1. Leg formula: 2431. Length of palp and legs as in Table 2.

Palpal tarsus longer than tibia. Chelicera with three teeth on anterior and posterior margins respectively, and several denticles between them. Embolus arising from tegulum in 8-o'clock-position, slightly slender. Dorsal part of RTA 


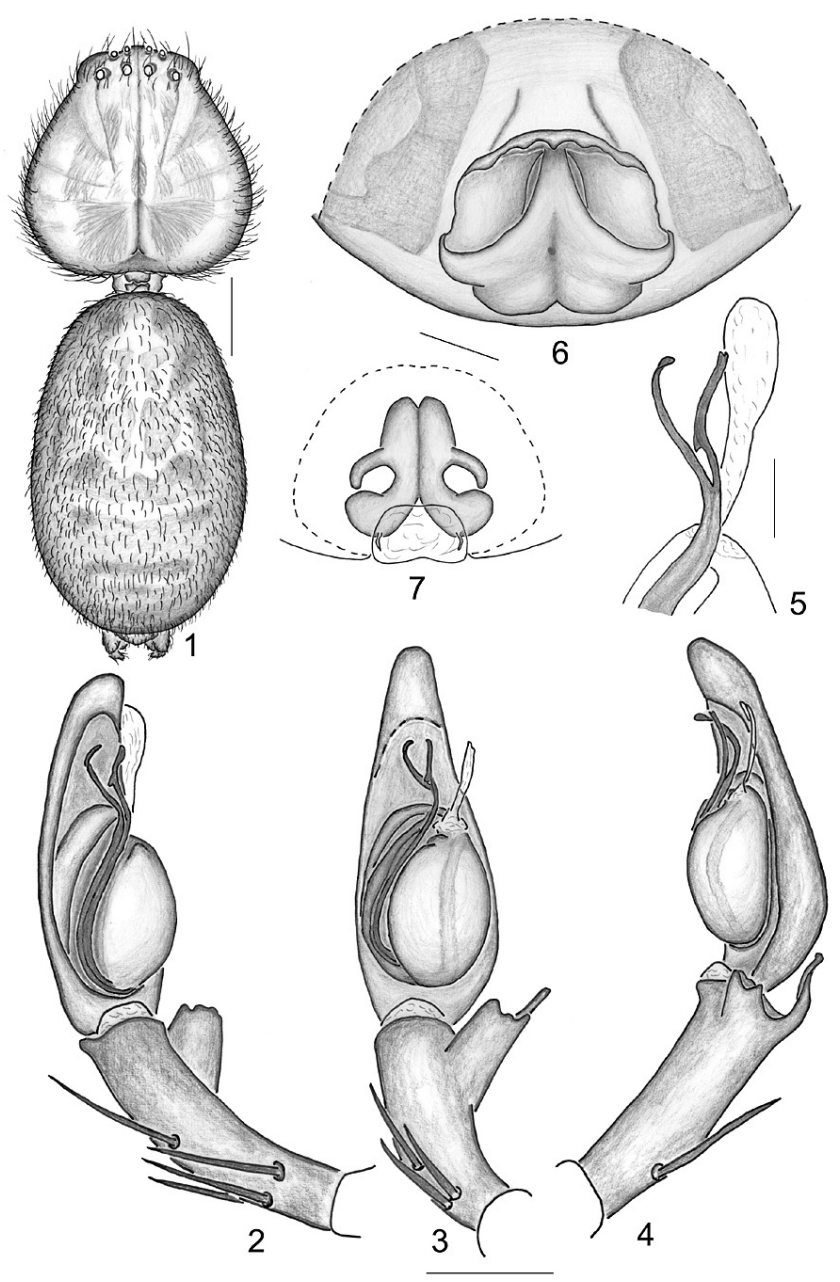

Figs. 1-7. Sinopoda mi sp. nov., male holotype and female paratype. - 1, male habitus, dorsal view; 2 , male left palp, prolateral view; 3 , male left palp ventral view; 4, male left palp, retrolateral view; 5 , tip of embolus with conductor, ventral view; 6 , female genitalia, ventral view; 7 , female genitalia, dorsal view. Scale bar: 1, $2 \mathrm{~mm} ; 2-4,0.8 \mathrm{~mm} ; 5,0.2 \mathrm{~mm} ; 6-7,0.4$ mm.

slender, digitiform, bent, slightly S-shaped and obtuse at apex, ventral part triangle-shaped with concave in retrolateral view (Fig. 4). Sperm duct almost straight (Fig. $3)$.

Color. Prosoma yellowish, with irregular dark markings formed by long dark lodged hairs, and with marginal hairs on carapace (Fig. 1); radial pattern of carapace distinct; chelicera darker; sternum and coxae lighter, yellowish; sternum without darker margin. Opisthosoma dorsally dark and hairy, with dark markings, four pairs of dark spots and a dark posterior transversal band (Fig. 1); ventrally hairy, gray.

Female (paratype). Similar in overall appearance to male, but slightly bigger and darker. PL 6.02, PW 4.90, AW 3.06, OL 6.22, OW 4.08. Eye sizes and interdistances: AME 0.18, ALE 0.33, PME 0.25, PLE 0.35, AME-AME 0.30, AME-ALE 0.15, PME-PME 0.43, PME-PLE 0.48, AME-PME 0.44, ALE-PLE 0.45, CH (AME) 0.40, CH
Table 1. Spination of Sinopoda mi (male holotype).

\begin{tabular}{lccccc}
\hline & Palp & Leg I & Leg II & Leg III & Leg IV \\
\hline Femur & 1310 & 2230 & 3130 & 3130 & 1330 \\
Patella & 1010 & 1010 & 1010 & 1010 & 0010 \\
Tibia & 1210 & 1318 & 1318 & 2326 & 2226 \\
Metatarsus & - & 1014 & 1014 & 3036 & 3036 \\
\hline
\end{tabular}

Table 2. Length of palp and legs of Sinopoda mi (male holotype).

\begin{tabular}{lccccc}
\hline & Palp & Leg I & Leg II & Leg III & Leg IV \\
\hline Femur & 3.57 & 5.51 & 8.26 & 7.04 & 7.14 \\
Patella & 1.58 & 2.04 & 3.06 & 2.65 & 2.35 \\
Tibia & 1.94 & 5.61 & 8.98 & 6.43 & 7.04 \\
Metatarsus & - & 5.71 & 9.59 & 6.63 & 8.06 \\
Tarsus & 2.30 & 2.14 & 2.55 & 2.14 & 2.55 \\
Total & 9.38 & 21.11 & 32.44 & 24.89 & 27.13 \\
\hline
\end{tabular}

Table 3. Spination of Sinopoda mi (female paratype).

\begin{tabular}{lccccc}
\hline & Palp & Leg I & Leg II & Leg III & Leg IV \\
\hline Femur & 1310 & 3230 & 3130 & 3230 & 1330 \\
Patella & 1010 & 1000 & 1000 & 0000 & 0000 \\
Tibia & 2130 & 1018 & 1018 & 2026 & 2026 \\
Metatarsus & 3030 & 1014 & 1026 & 1016 & 3036 \\
\hline
\end{tabular}

Table 4. Length of palp and legs of Sinopoda mi (female paratype).

\begin{tabular}{lccccc}
\hline & Palp & Leg I & Leg II & Leg III & Leg IV \\
\hline Femur & 2.41 & 5.92 & 6.53 & 6.33 & 5.92 \\
Patella & 1.29 & 2.55 & 2.65 & 2.55 & 2.24 \\
Tibia & 1.55 & 4.49 & 6.22 & 6.22 & 5.61 \\
Metatarsus & - & 5.00 & 5.51 & 5.41 & 5.71 \\
Tarsus & 2.08 & 1.43 & 1.33 & 1.73 & 2.04 \\
Total & 7.33 & 19.38 & 22.24 & 22.24 & 21.52 \\
\hline
\end{tabular}

(ALE) 0.33, SL 2.54, SW 2.61. Spination as in Table 3. Leg formula: 2(3)41. Length of palp and legs as in Table 4.

Palpal claw with 8 teeth. Epigynal field approximately quadrate, with two long anterior bands, slightly bent (Fig. 16); posterior part of vulva wider than anterior (Fig. 7).

Color: Similar to male.

Distribution. Known only from the type locality.

Etymology. The specific name refers to the type locality, Mi Cave. The "mi" from the Tujia's language means "water enters a cave, falls down, and then disappears".

Natural history. Specimens of this species were collected from entrance zone of the cave (light zone). The cave is huge, maybe 100 metres deep, foggy and moist; a stream flows into its opening and along it forward, and then falls down. Spiders were found under stones and in gravel.

\section{Acknowledgments}

Mr. T. Fan, Chengdu Institute of Biology, Chinese Academy of Sciences supported our biospeleology studies in Guizhou province. We thank Dr. Shun-Ichi Ueno, Department of Zoology, National Science Museum of Japan and Dr. Yoshiaki Nishikawa, Biological Laboratory, Otemon Gakuin University of Japan who assisted in the speleological explorations and collection of specimens, and provided some speleological literatures. This study was supported in part by the Spider Diversity of Guizhou province project, funded by the Guizhou provincial Science Foundation (2005-2019). 


\section{References}

Jäger, P. 1999. Sinopoda, a new genus of Heteropodinae (Araneae, Sparassidae) from Asia. J. Arachnol., 27: 19-24.

Jäger, P., Gao, J. C. \& Fei, R. I. 2002. Sparassidae in China II. Species from the collection in Changchun (Arachnida: Araneae). Acta Arachnol., 51: 23-31.

Jäger, P. \& Ono, H. 2000. Sparassidae of Japan. I. New species of Olios, Heteropoda, and Sinopoda, with notes on some known species (Araneae: Sparassidae: Sparassinae and Heteropodinae). Acta Arachnol., 49: 41-60.

Jäger, P. \& Ono, H. 2001. First records of the genera Pseudopoda, Sinopoda, and Olios from Taiwan with descriptions of four new species (Araneae: Sparassidae). Acta Arachnol., 50: 21-29.

Jäger, P. \& Ono, H. 2002. Sparassidae from Japan. II. First
Pseudopoda species and new Sinopoda species (Araneae: Sparassidae). Acta Arachnol., 51: 109-124.

Jäger, P. \& Yin, C. M. 2001. Sparassidae in China. I. Revised list of known species with new transfers, new synonymies and type designations (Arachnida: Araneae). Acta Arachnol., 50: 123-134.

Liu, J., Li, S. Q. \& Jäger, P. 2008. New cave-dwelling huntsman spider species of the genus Sinopoda (Aranei: Sparassidae: Heteropodinae) from China. Zootaxa, 1857: 1-20.

Platnick, N. I. 2008. The world Spider Catalog, Version 9.5. American Museum of Natural History, online at http://research. amnh.org/entomology/spider/catalog/COUNTS.html.

Song, D. X., Zhu, M. S. \& Chen, J. 1999. The Spiders of China. Hebei Sci. Technol. Publ. House, Shijiazhuang, 640 pp.

Received September 15, 2008 / Accepted May 5, 2009 